Montalvo, Blanca.

Profesor contratado doctor, Universidad de Málaga, Departamento de Arte y Arquitectura, DIANA (Diseño de Interfaces Avanzados).

Martínez Silvente, Ma Jesús.

Profesor contratado doctor, Universidad de Málaga, Departamento de Ha del arte, HUM 130.

\title{
El lugar y sus habitantes: \\ Sobre el fotoensayo Sense of Place.
}

\section{The place and its inhabitants: \\ Sense of Place: photo essay.}

TIPO DE TRABAJO:

Comunicación.

PALABRAS CLAVE:

Lugar, personas, narración, sentido.

KEY WORDS:

Place, people, narration, sense.

RESUMEN.

La ponencia que presentamos trata de revisar el proceso de trabajo del libro de fotografías Sense of Place. Este proyecto es fruto de la colaboración entre una historiadora del arte y una artista. Comenzó con una estancia de investigación de las dos en Inglaterra en 2014, y fue publicado en Málaga en 2016. A lo largo de la ponencia analizaremos el tema tratado y lo compararemos con otros enfoques teóricos y prácticos; exploraremos el proceso de trabajo de ambas y la forma en que las relaciones personales influyen en el proceso creativo; y para terminar, comentaremos el proceso de edición y distribución.

ABSTRACT.

The paper that we present tries to review the work process of the Sense of Place picture book. This project is the result of collaboration between an art historian and an artist. It began with a research stay of the two in England in 2014, and was published in Malaga in 2016. Throughout the paper we will analyze the subject treated and compare it with other theoretical and practical approaches; We will explore the work process of both and how personal relationships influence the creative process; And finally, we will comment on the editing and distribution process. 


\section{CONTENIDO}

\section{ÉRASE UNA VEZ...}

El libro de fotos Sense of Place surge como parte de un proyecto en colaboración. Hace unos años estábamos preparando la documentación para solicitar una estancia en Inglaterra. Cada una teníamos una investigación independiente, pero ya que íbamos a coincidir en el destino y sospechábamos que en parte del viaje, decidimos colaborar en algún formato que combinara imagen y texto. El libro de fotografías surgió como primera propuesta: una se encargaría del texto y otra de la imagen. Faltaba todo lo demás por decidir: el tema, el lenguaje, el tono, el formato, etc.
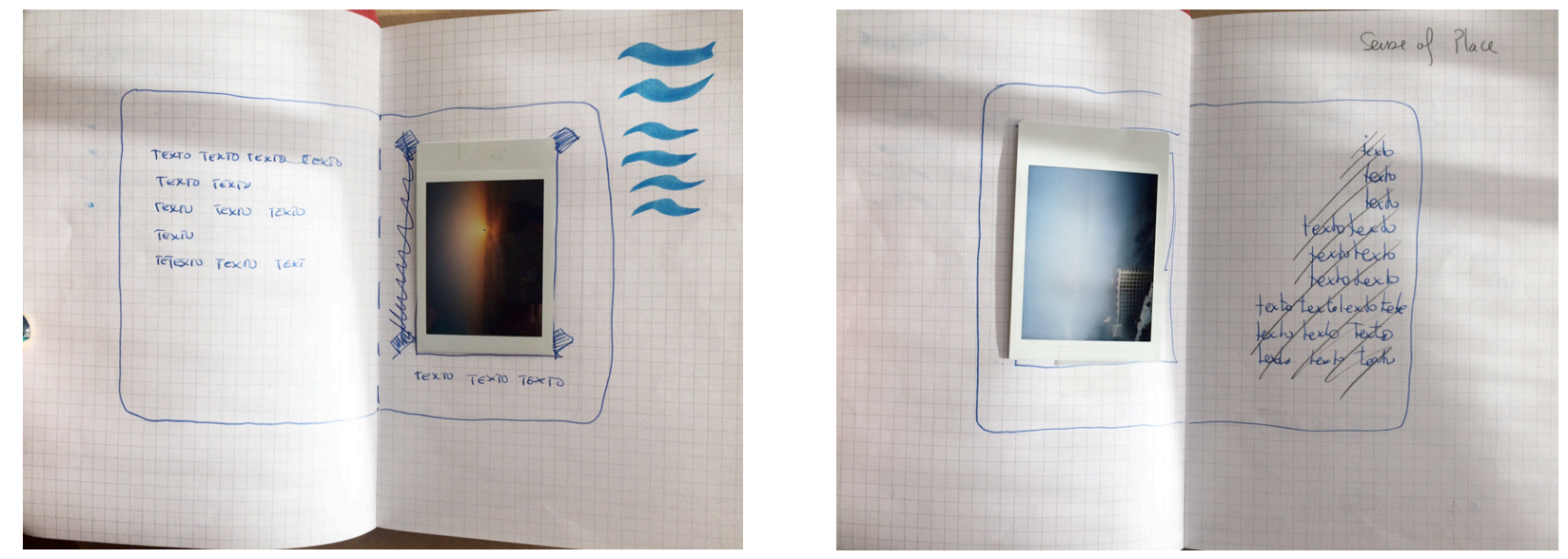

Ilustración 1: bocetos Sense of Place. Blanca Montalvo. Libreta 2013.

Durante el viaje y la estancia en Inglaterra realizamos fotografías de los lugares y las gentes con las que nos cruzábamos. Recuerdo un día que al revisar las imágenes, observamos la diferencia entre aquellas de los lugares típicos y famosos que todos fotografiamos, aficionados y profesionales, frente a otras algo anodinas y casuales. En ese momento el proyecto empezó a tener un carácter específico.

Durante el proceso de toma de imágenes y la selección y orden hasta el diseño del formato definitivo trabajamos por separado. De manera que el texto que hay en el libro se encontró con las imágenes casi dos años después de ver las primeras pruebas.

El título del libro surge durante la primera etapa. Es una referencia directa al geógrafo australiano George Seddon, quien analiza el lugar atendiendo a dos presupuestos casi opuestas: por un lado atiende a las características específicas y únicas que cada lugar tiene, en relación al clima, la geografía la vegetación, etc.; y por otro lado y al mismo tiempo, también reflexiona sobre el sentimiento y la percepción que las personas tienen de ese lugar. Por ello, desde el principio, las fotografías muestran una dualidad entre espacios fotografiados y las personas que los habitan.

\section{CÓMPLICES DE LA IMAGEN.}

El fash de magnesio que utilizaba Jacob Riis en sus incursiones en el Lower East Side de Nueva York, sorprendía a los pobres acinados en condiciones paupérrimas, al tiempo que trataba de reformar una sociedad que se negaba a ver o reconocer la pobreza. El fogonazo permitía acceder a lo desconocido, al tiempo que mostraba unos sujetos extrañados que miraban a la luz que interrumpía su miseria. Podríamos decir que estamos en la era del Homo Photographicus (Fontcuberta, 2016, 31).

El primer reportaje fotográfico de la historia fue publicado por Nadar en Le Journal Illustré, en 1886. Una foto entrevista con motivo del cumpleaños de Michel Eugene Chevreul. Una secuencia de imágenes desenfadadas e intimistas que representa una vivaz conversación entre amigos con unos pie de página que confirmaba lo que vemos en las imágenes. Hay una intención de colocar al espectador en la habitación, como un invitado más a esta celebración. Con el principio de siglo llegó la innovación a la prensa, y hasta los años 40 se hacían complejas maquetaciones influenciadas por Dadá y el surrealismo, con collages que combinaban imagen y texto. La prensa ilustrada francesa y británica creó un híbrido entre fotografía y tipografía, justo antes del gran éxito de las revistas ilustradas 
americanas, influenciadas en su primera época por el realismo descarnado de las misiones fotográficas y en la segunda por el sueño del American Everyday Life. (Hostetler, 2000).

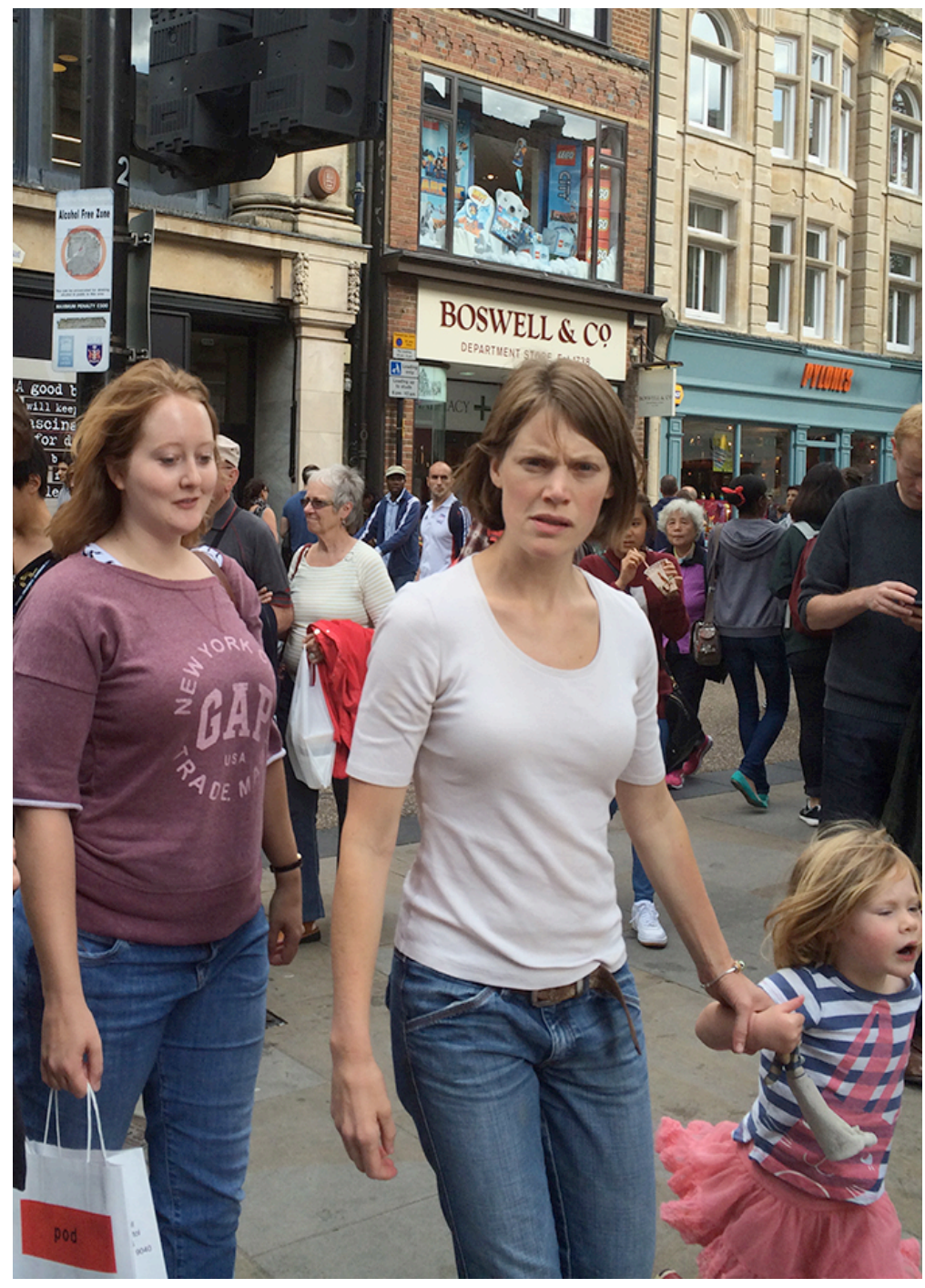

llustración 2: Sense of Place \#7. Blanca Montalvo. 2016.

En España en los años 50 hubo una obsesión por la realidad. La fotografía moderna de preguerra había desaparecido: Josep Renau, Walter Reuter, y José Suárez estaban en el exilio americano. Sibylle von Kaskel, José val del Omar y Cecilio Paniagua habían abandonado la fotografía. La Agrupación Fotográfica de Almería (AFAL), con dirección de José Ma Artero y Carlos Pérez Siquier, se convirtió en el principal impulsor de la renovación, a través de la fotografía humanista y documental inspirada por Cartier-Bresson William Klein, Robert Frank y Otto Steiner. Hubo un ligero aperturismo económico y algunas tendencias políticas, que convirtieron a nuestro país en el decorado ideal para los fotógrafos que querían documentar lo que iba a perderse, o ilustrar con sus imágenes sus ideales políticos. Uno de los proyectos más famosos fue el que publicó en 1951 Eugene Smith en Life: "Spanish Village". Un tratado sobre la pobreza en España que tuvo un gran impacto político dentro y fuera del país. Smith era un fotógrafo centrado en el ser humano y su relación con el entorno. En Deleitosa, un pueblo de Cáceres, tomó más de 1500 fotografías. Convivió y se entrevistó con sus habitantes. Anotaba sus nombres y condiciones de vida, en un informe de más de 24 páginas en las que analizaba la economía de subsistencia del pueblo, basada en la agricultura; también atendió al analfabetismo y las condiciones de pobreza extrema y todos aquellos problemas de un país afectado por las secuelas de la Guerra Civil. 
Otro gran hito de los 50 fue la exposición The Family Man, organizada por Edward Steichen en MOMA (1955): 503 fotografías; 270 fotógrafos de 68 países (ningún español). La muestra tuvo como objeto generar una visión universal y solidaria de las sociedades humanas, centrándose en los individuos, con sus particularidades y singularidades, "pero subrayando los nexos de unión frente al amor, el trabajo, la familia, la muerte, la guerra o la paz" (Marzo \& Mayayo 2015, 231)

En los 80 en España la fotografía fue integrada en el relato de la movida, y se convirtió en el vehículo de transmisión de las nuevas identidades sociales. A diferencia de los fotógrafos de comienzos de los 70, como Cristina García Rodero, Alberto Schommer, Koldo Chamorro, Jorge Rueda o Xurxo Lobato, cuyo trabajo consistió en interpretar la pulsión de las tradiciones, en retratar el sentido de comunidad y analizar el choque entre modernidad y cotidianeidad. "Los fotógrafos de la movida articularon su mirada desde un ángulo más oblicuo, aparentemente alejado de un interés social o político" (Smith 2000, 46). Esta nueva estética fue muy apreciada fuera. Un ejemplo es la serie que realizó Mary Ellen Mark en 1985 para Rolling Stone: "The New Spain". ${ }^{1}$

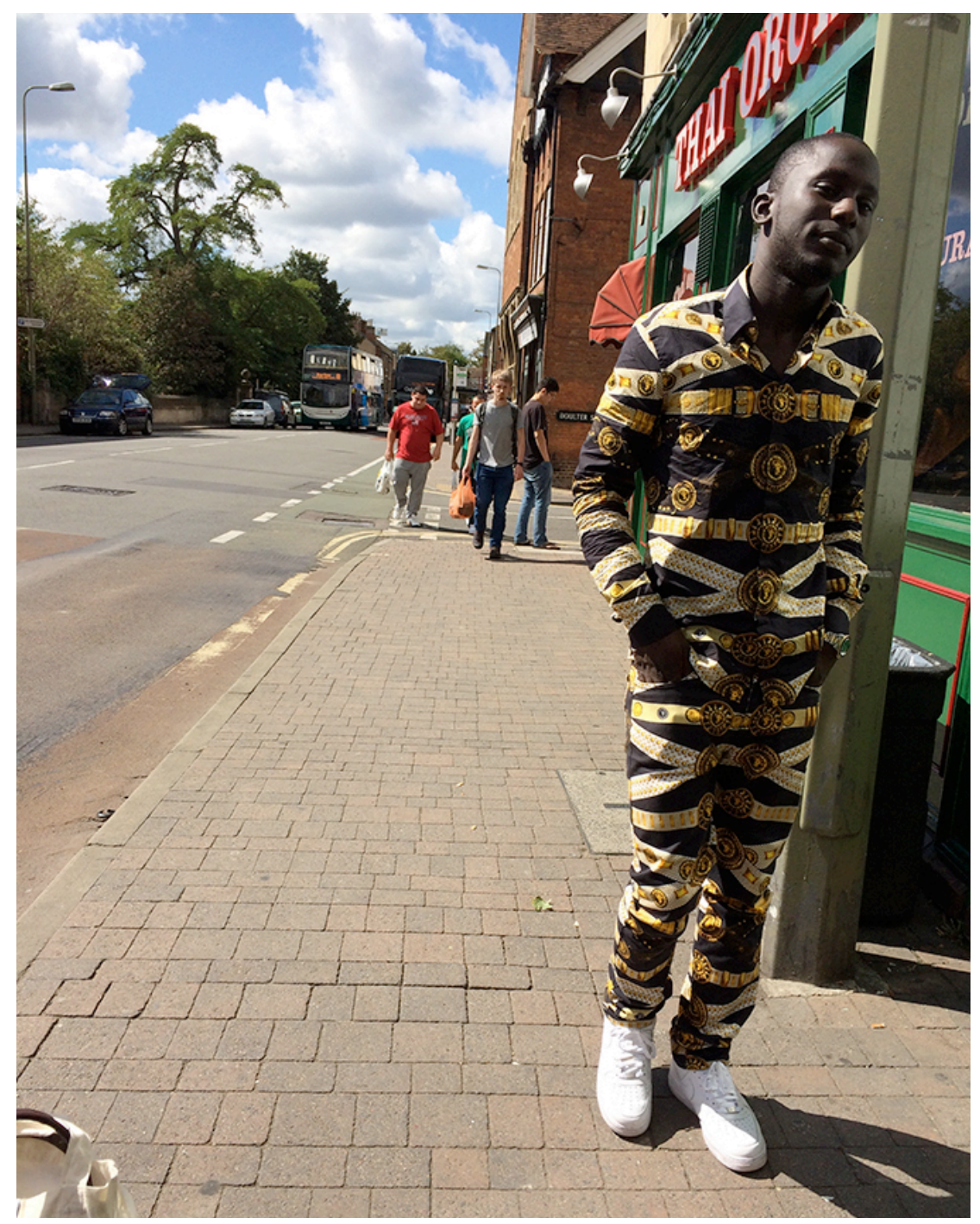

llustración 3: Sense of Place \#9. Blanca Montalvo. 2016.

Como vemos, desde que la fotografía existe se debate entre la sencillez y la imagen compuesta. Desde sus orígenes explora un estilo amateur y realista. Casi una falta de estilo que nos acerque a la inmediatez, alejándonos de ella, pues son las imágenes de los profesionales las que parecen falsamente sencillas. Los personajes retratados en el libro son anónimos, casuales y sin ningún interés especial. Excepto esa mirada cómplice al objetivo, que muestra en su rostro la reacción al ser fotografiados. Este público anónimo que

${ }^{1}$ Disponible en la web de la fotógrafa: http://www.maryellenmark.com/text/magazines/rolling\%20stone/920S-000-002.html (marzo 2017) 


\author{
Montalvo, Blanca y Martínez Silvente, Mạ Jesús \\ El lugar y sus habitantes. Sobre el fotoensayo Sense of Place \\ III CONGRESO INTERNACIONAL DE INVESTIGACIÓN EN ARTES VISUALES :: ANIAV 2017 :: GLOCAL [codificar, mediar, transformar, vivir] \\ http://dx.doi.org/10.4995/ANIAV.2017.4888
}

nos cruzamos al caminar por cualquier ciudad (Oxford, Londres, Madrid, Málaga...) público, modelo o fotógrafo, podrían estar al otro lado del objetivo, al otro lado de la pantalla.

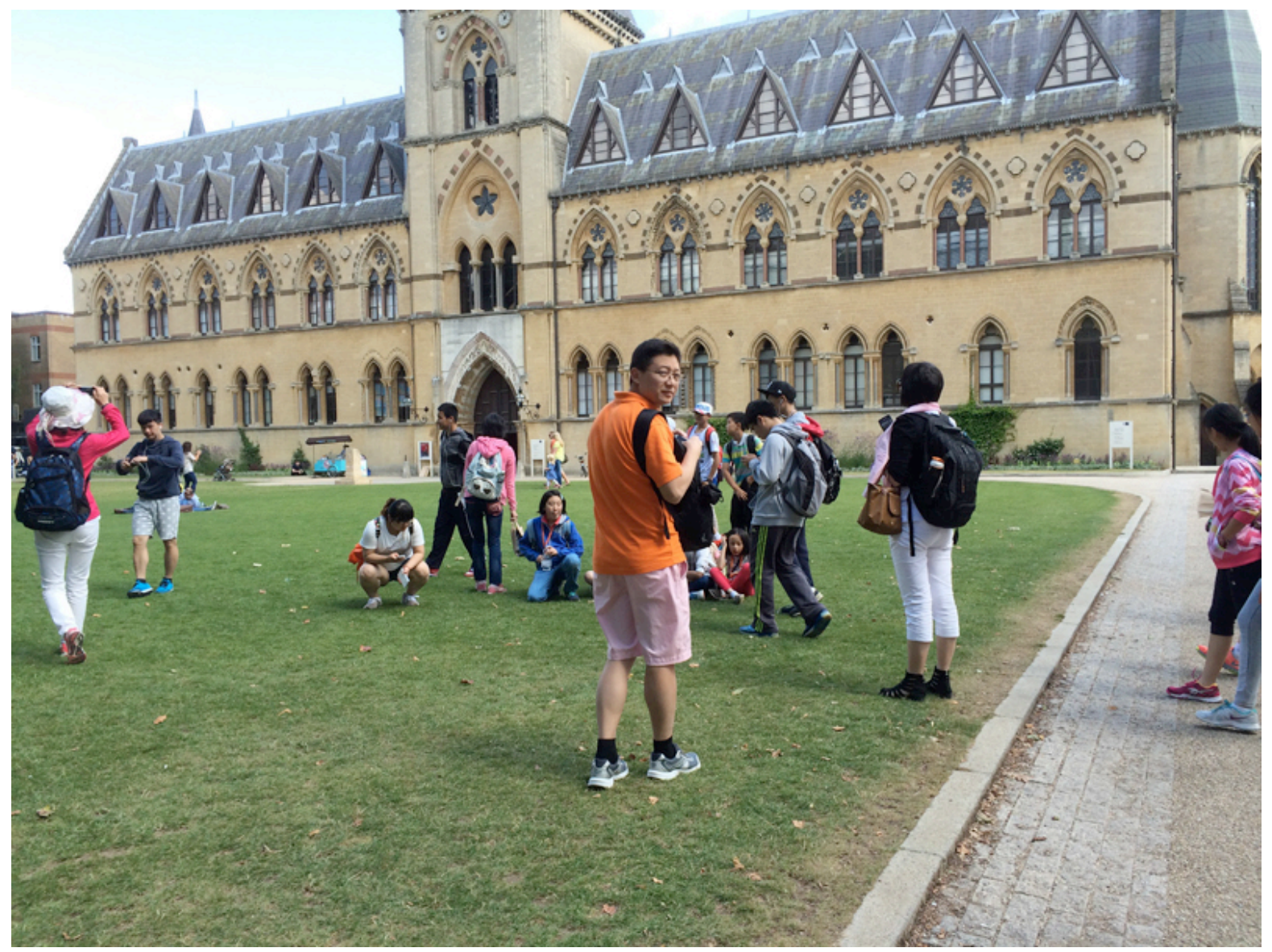

Ilustración 4: Sense of Place \#21. Blanca Montalvo. 2016.

\title{
EN EL LUGAR Y FRENTE A ÉL
}

Vemos el mundo a través del objetivo. El rincón de la cocina de una granja humilde de Alabama a través de las fotos que hizo Walker Evans a principios de los 60. El París nocturno y brumoso de Brassai, imaginado una y otra vez desde la década de los años 30 hasta su muerte. Es difícil hacer fotografías de lo cotidiano, porque la tendencia natural es a dar por hecho la realidad ordinaria y considerarla aburrida. Ante estos autores, la realidad es siempre fascinante. Robert Smithson se apasiona por un viejo edificio a medio remodelar en México. Hotel Palenque, realizada en 1969, se trata de un carrusel de diapositivas acompañadas de la grabación de una conferencia en la Universidad de Utah. Las imágenes muestran la realidad del entorno del hotel en la que se vierten diferentes estados, lo depauperado y lo incipiente, lo renovado y lo obsoleto. Se observa en estas diapositivas la presencia de la noción de "entropía" defendida por el artista y se cristaliza su interés por la dimensión temporal del arte, por la reflexión en torno al lugar y la relación entre el ser humano y su entorno natural, así como el diálogo entre espacio real y espacio metafórico. Hotel Palenque muestra los estratos del tiempo a partir de la intención de hacer visibles las sucesivas reformas que del hotel hicieron sus dueños. Fragmentos de un lugar cualquiera.

Otros autores se enfrentan a lugar eliminando la acción y el tiempo. Pavel Maria Smejkal en la serie Fatescapes (2009-2011) desprovee a la fotografía del suceso que tuvo lugar en ella y que motivó la toma, de manera que sólo queda el fondo, el paisaje, tal vez lo único verdaderamente real..., porque el resto es una construcción, una imagen encaminada a condicionar la opinión pública: el miliciano abatido en el cerro Muriano de Capa; los marines izando la bandera en Iwo Jima, de Joe Roesenthal; la ejecución de un presunto miembro del Vietcong con un tiro en la sien, de Eddie Adams; el niño famélico amenazado por un buitre en Sudán, de Kevin Carter; y así en una larga lista de lugares reconocibles, más allá del tiempo de la acción eliminada. Los Fatescapes parecen trasladarnos 
a unos paisajes que carecen de la temporalidad de la mirada, desprovistos de una conciencia humana que los observe y presienta su duración.

Los instantes decisivos son relegados por los indecisivos, como en la serie Trop Tôt, Trop Tard (2007-2008), de Isabelle Le Minh, donde manipula caramáticas obras de Cartier-Bresson, desposeyéndolas de elementos de acción, deja el escenario vacío. Destaca la oposición entre el no-pasar-nada y el momento justo. Al robar el tiempo de la imagen, destaca por su ausencia, en un juego con la memoria del espectador, que se sorprende frente al interés de estos lugares vacíos, convertidos ya para siempre en ausencias.

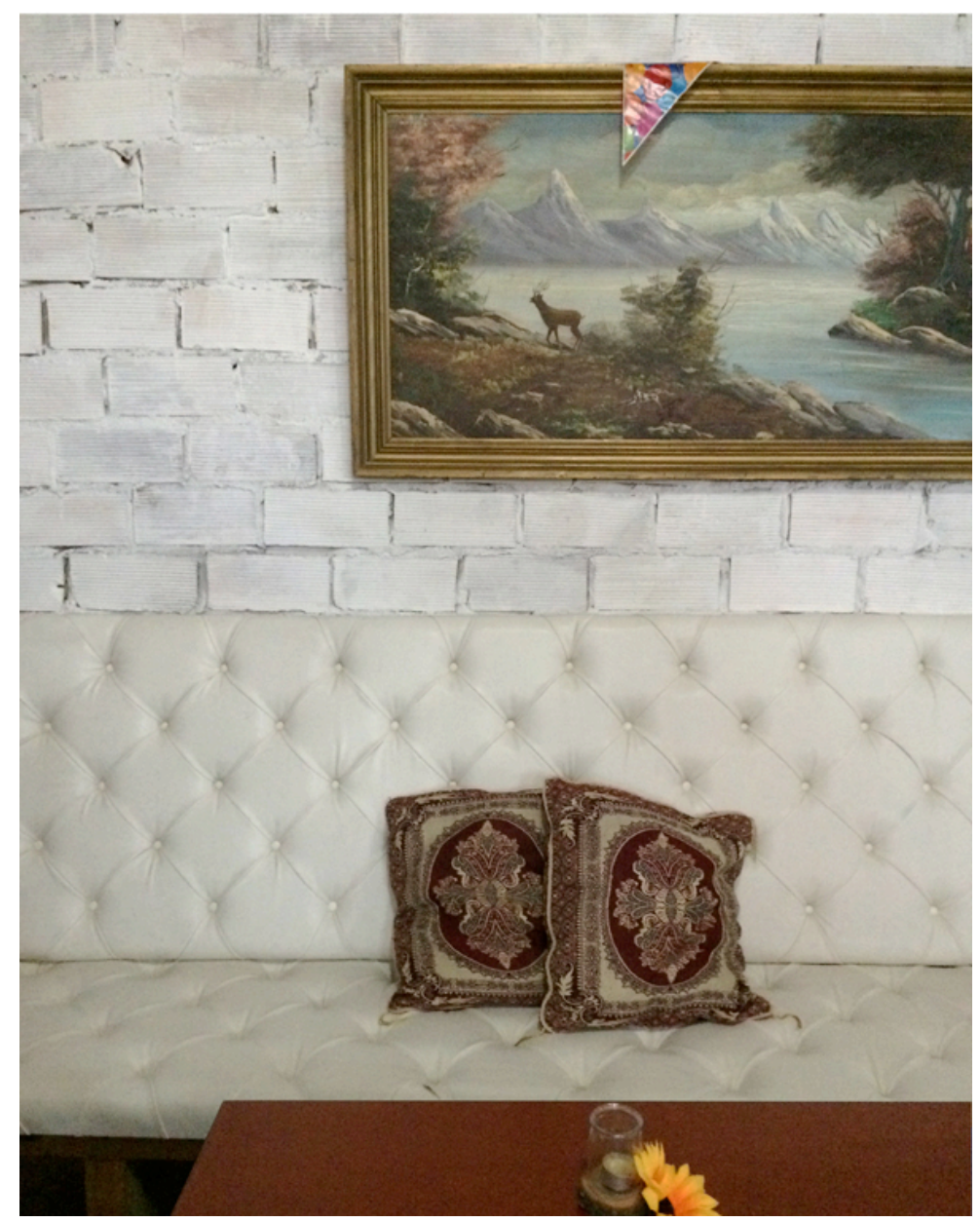

llustración 5: Sense of Place \#25. Blanca Montalvo. 2016.

Miguel Angel Tornero ${ }^{2}$ combina de forma aleatoria las imágenes de las ciudades en que habita. Deja la composición al programa, que genera la extrañeza de esas combinaciones imposibles antinatura, tan reales.

Parte de las imágenes que se muestran en Sense of Place son de la serie Lugares imposibles. Un proyecto informe que data de lejos y se distribuye a través de Instagram. Instantáneas que, por su austeridad -por carecer de un antes y un después- producen un extrañamiento que roza lo metafísico. Por lo general, son escenas despobladas que se caracterizan por la sensación de soledad y abandono que producen en el espectador que, por su parte, nunca verá esclarecido el misterio; como apuntara Dubois, no es más que un instante convertido en imagen que "no explica, no interpreta y no comenta", es y siempre será "muda, desnuda, llana, opaca" (Dubois, 2002, 31)

\footnotetext{
${ }^{2}$ Se pueden ver imágenes de las Random Series en la web del artista: http://miguelangeltornero.net/the-random-series--madrileo-trip(marzo 2017)
} 


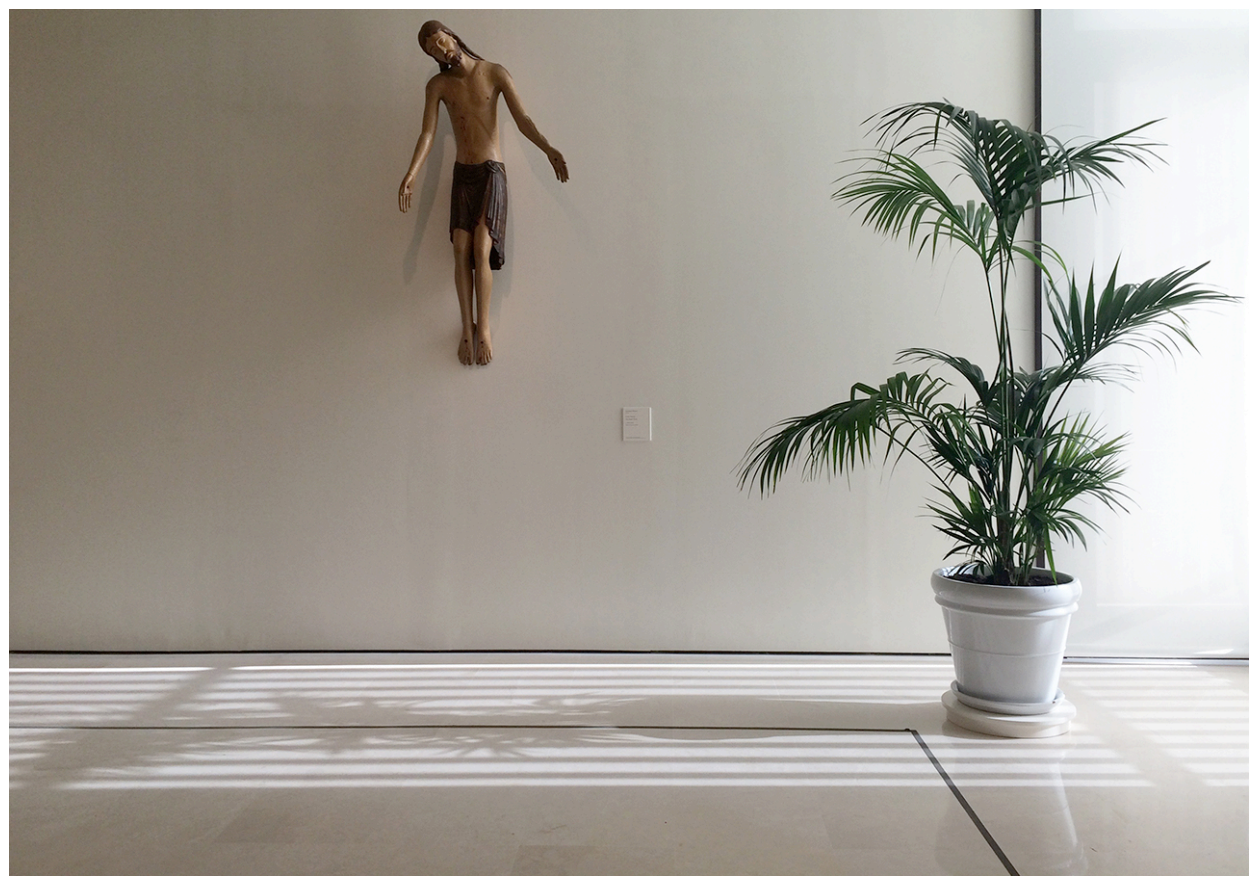

Ilustración 6: Sense of Place \#51. Blanca Montalvo. 2016.

\section{CONCLUSIONES}

Cualquier instante. Cualquier lugar. Cualquiera. Estamos inmersos en una inflación de imágenes. Todos somos autores, modelos y distribuidores. Se multiplican a nuestro alrededor, como si viviéramos en un salón de espejos. ¿Por qué seguir haciendo fotos? No parece que haya una respuesta sencilla a esta pregunta. Quizás si preguntamos: ¿qué podemos fotografiar hoy? El gesto de fotografiar como pregunta por el mundo, más que como respuesta exhibicionista. En el momento más insospechado, cuando parece que no ocurre nada, un escenario se convierte en el caldo de cultivo para el atesoramiento de unas fuentes que pueden estar destinadas a un fin, o no. La conclusión de un proyecto artístico no puede ser más que otras preguntas y nuevos proyectos.

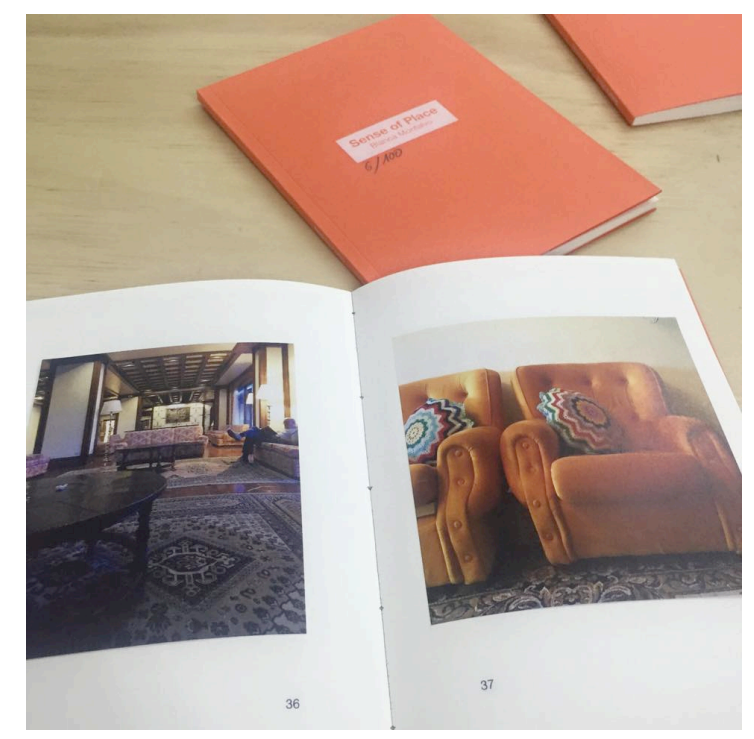

Ilustración 8: Sense of Place. Blanca Montalvo. 2016. 


\section{FUENTES REFERENCIALES.}

AAVV. 2008. Lugares comprometidos. Topografía y actualidad. Fundación ICO LA Fábrica. Madrid.

DUBOIS, Philippe. 2002. El acto fotográfico. De la representación a la recepción. Paidós. Barcelona.

FONTCUBERTA, Joan. 2016. La furia de las imágenes. Círculo de lectores. Barcelona.

HOSTETLER, Lisa. "Photography and Everyday Life in America, 1945-60." In Heilbrunn Timeline of Art History. New York: The Metropolitan Museum of Art, 2000-. http://www.metmuseum.org/toah/hd/phev/hd_phev.htm (marzo 2017)

LE MINH, Isabelle. Web de la artista: http://www.theshadowswilltakecareofthemselves.net (marzo 2017)

MARK, Mary Ellen. Web de la artista: www.maryellenmark.com (marzo 2017)

MARZO, Jorge Luis y MAYAYO, Patricia. 2015. Arte en España: Ideas, Prácticas, Políticas. 1939-2015. Cátedra

MONTALVO, Blanca. 2016. Sense of Place. Los Interventores. Málaga.

MONTALVO, Blanca. Web de la artista: www.blancamontalvo.com (marzo 2017)

SEDDON, George. 1972. Sense of Place. A Response to an environment, the Swan Coastal Plain Western Australia. Perth: University of western Australia Press.

SMITH, Paul Julian. 2000. The Moderns. Time, Space, and Subjectivity in Contemporary Spanish Culture. Oxford Univ. Press. Oxford.

SMEJKAL, Pavel Maria. Web de la artista: http://www.pavelmaria.com (marzo 2017)

TORNERO, Miguel Ángel. Web del artista: http://miguelangeltornero.net (marzo 2017) 